\title{
Questões de método e pesquisa dos dispositivos institucionais de confinamento do presente
}

\section{Questions of method and research of the institutional devices of confinement of the present}

\section{Manoel Mendonça Filho*}

Professor dos Núcleos de Pós-Graduação em Educação e em Psicologia da Universidade Federal do Sergipe - UFS, Aracaju, SE, Brasil

\section{Michele de Freitas Faria de Vasconcelos**}

Doutoranda em Educação pela Universidade Federal do Rio Grande do Sul - UFRGS, Porto Alegre, RS, Brasil

\begin{abstract}
RESUMO
Partimos de uma análise de conjuntura que marca no Brasil, nos últimos 30 anos, processos de precarização do trabalho, hegemonia do capital financeiro especulativo sobre a produção, gestão retórica das imagens como modo de dominação e disseminação do confinamento como dispositivo de controle, resultando na desqualificação da vida posta à disposição do tecnicismo vazio de sentido. Contrastando suas experiências com o pano de fundo da imagem 'Estado capitalista financeiro no Brasil', dois pesquisadores entrelaçam problemas de pesquisa: análise dos modos de objetivação das denominadas 'políticas públicas' de segurança (mais especificamente o sistema prisional) e saúde mental (serviços substitutivos de saúde mental). Problematiza-se como tais 'políticas' se articulam e compõem com o boom do confinamento dos últimos anos. Aqui apresentadas como 'etno-pesquisainterferência', de inspiração foucaultiana em conversa com as formulações mais recentes da sócio-análise francesa e da Etnometodologia, articula-se um modo pesquisante pelo qual procedimentos, técnicas e instrumentos se constituem orientados pelo imperativo estratégico do método, que é ao fim e ao cabo, uma decisão político-afetiva de compromisso com a ativação do desejo nas pessoas como alternativa.
\end{abstract}

Palavras-chave: Pesquisa interferência, Método, Capitalismo financeiro, Confinamento, Políticas públicas.

\begin{abstract}
The article begins with a conjunctural analysis which sets, in the last 30 years, work instability processes, hegemony of speculative financial capital over production, rhetoric management of images as a way to domination and dissemination of confinement as a control mechanism which results in the disqualification of life put at disposal of meaningless technicism. Setting their experiences against the backcloth of the 'financial capitalism State in Brazil' image, two researchers intertwine research issues: the analysis of modes of objectification of the so-called security (more specifically the prison system) and mental health (substitutive mental health services) 'public policies'. It is analyzed how such 'policies' articulate and make up
\end{abstract}


with the confinement boom of the last years. Here presented as ethnointerference research, of foucaultian inspiration in dialogue with the most recent formulations of French social analysis and Ethno-methodology, it articulates a way of making research in which proceedings, techniques and instruments constitute themselves oriented by strategic imperative of method that is, at the end, a political-affective decision of commitment with the activation of desire in people as an alternative.

Keywords: Interference research, Method, Financial capitalism, Confinement, Public policies.

\section{Boom do confinamento}

Em "A história da loucura", Foucault (2004, p. 399) afirma que o isolamento/internamento do louco articula-se com a crise dos hospitais gerais, ou seja, da era do grande internamento, "uma crise que não se liga a protestos políticos, mas que sobe lentamente de todo um horizonte econômico e social". Para ele, o nascimento do hospício no século XIX "respondia demasiadamente a uma necessidade real". Nesse cenário, se o internamento ainda fazia sentido, dizia respeito a uma "população indigente", incapaz de prover a suas necessidades.

É que, no contexto das sociedades de produção e, mais tarde, do capitalismo industrial, dá-se a transformação da população pobre em população produtiva:

Há aí toda uma reabilitação moral do Pobre, que designa, mais profundamente, uma reintegração econômica e social de sua personagem. Na economia mercantilista, não sendo nem produtor nem consumidor, o Pobre não tinha lugar: ocioso, vagabundo, desempregado, sua esfera era a do internamento, medida com a qual era exilado e como que abstraído da sociedade. Com a indústria nascente, que tem necessidade de braços, faz parte novamente do corpo da nação, produzindo-se, então, uma relação entre pobreza e população, [...] uma população será tanto mais preciosa quanto mais numerosa for, pois oferecerá à indústria uma mão-de-obra barata. (FOUCAULT, 2004, p. 405-06)

Se o internamento é passível de crítica "pelas incidências que pode ter sobre o mercado de mão-de-obra", ele o é ainda mais "porque constitui, e com ele toda a obra da caridade tradicional, um financiamento perigoso" (FOUCAULT, 2004, p. 407). Gesta-se outro modo de inserção da pobreza: "as mulheres de vida alegre que, levadas para as manufaturas do interior, poderiam tornar-se mulheres trabalhadoras?" (FOUCAULT, 2004, p. 397).

Nesse panorama em que se desenvolve a idéia de pobre como população produtiva, gesta-se a concepção de trabalhador livre, tratando-se, porém de uma liberdade restrita, de um indivíduo que, 
da perspectiva da produção, só conta como força de trabalho, ou seja, só é livre para vender sua mão de obra.

Aqui cabe uma pergunta: "uma vez retirada toda essa população, o que sobraria nas casas de internamento? Os que não podem ser colocados em nenhum outro lugar" (FOUCAULT, 2004, p. 397), os pobres que não estão aptos a produzir, que não podem ser utilizados pela engrenagem capitalística ${ }^{1}$. A esses, o destino é o internamento: loucos e criminosos ${ }^{2}$. No século XIX, então:

A loucura se individualiza, gêmea estranha do crime, pelo menos ligada a ela, por uma vizinhança ainda não posta em questão. Nesse internamento esvaziado de seu conteúdo, [nessa nova divisão], essas duas figuras subsistem sozinhas; as duas simbolizam o que pode haver de necessário no internamento: são elas que doravante se apresentam como as únicas que devem ser internadas. (FOUCAULT, 2004, p. 399)

E no contemporâneo? Que modos de confinamento/internamento, que "novos" corpos se individualizam e, ao sê-lo, são condenados a um carimbo-passaporte, ao isolamento-apagamento em espaços em que 'outros' se encarregam de seus corpos?

Com a passagem da era industrial, fordista, para a era do consumo, das imagens, enfim, para a contemporaneidade, estamos vivenciando a transposição das sociedades disciplinares para as sociedades de controle. Em tal processo, "as formas do complexo de relações de força que [...] prevalecem tendem mais à abertura do controle contínuo e permanente que ao fechamento descontínuo das instituições disciplinares" (PIOVEZANI FILHO, 2004, p. 145).

Com a entrada em cena do capital extraterritorial, as relações de poder tornam-se mais fluidas, mais invisíveis, cada vez menos coercitivas, escorregadias e fugidias, rejeitando, assim, qualquer confinamento territorial. Nessa direção, Bauman (1999) anuncia o fim do panóptico, o fim da era do engajamento mútuo entre supervisores e supervisionados, líderes e seguidores, capital e trabalho.

Se, nas sociedades disciplinares, o objetivo era esquadrinhar toda a população, bloqueando-se, para isso, a saída das pessoas de dentro dos pesados muros das Instituições Totais (GOFFMAN, 2001): escola, quartel, fábrica, hospital etc.; agora, a exclusão impede a entrada nos espaços onde funciona a sociedade de bens e serviços e as Instituições Totais funcionam como "bloqueadoras do escape desatualizam-se no contato com o espaço do capitalismo global traduzido em volátil, em ciberespaço [...] o banco de dados ilustra [...] essa [nova] espacialidade e o controle dos que não podem entrar" (BAPTISTA, 2001, p. 81). 
A esse respeito, afirma Coimbra (2001) que agora "aqueles que, não conseguirem ser 'domesticados', docilizados e tornados produtivos, são mostrados como 'perigo social' e, por extensão, dispensáveis". A autora conversa com Wacquant:

Acompanhando tudo isso o Estado não mais sustenta a infraestrutura indispensável ao funcionamento de uma sociedade e adota "uma política de erosão sistemática das instituições públicas". Abandona à lógica do mercado - do 'livre mercado' - e do 'cada um por si' segmentos inteiros da população, "em especial, aqueles que privados de todos os recursos [...] dependem completamente dele. É a política urbana do abandono concentrado ${ }^{3}$. (COIMBRA, 2001, p.251)

Todavia, vale pontuar que o processo de passagem acima apontado não se traduz numa oposição, e sim numa intensificação e generalização da lógica disciplinar:

[...] a crise contemporânea das instituições não significa que os espaços fechados que definiam os espaços limitados das instituições deixaram de existir, de maneira que a lógica que funcionava outrora principalmente no interior dos muros institucionais se estende, hoje, a todo o campo social. (HARDT, 2000, p. 369)

Conjuntura neoliberal em que o suposto Estado Democrático de Direito funciona 'de fato e de direito' como um Estado mínimo social e máximo penal. Aliadas a 'antigos' modos, presenciamos outras formas de confinamento, cuja imagem emblemática bem pode ser a da célula domiciliar onde se pede tudo por delivery, se paga contas com um cartão, ou ainda melhor, via computador. 'Lar' de um corpo que compra, que viaja, que se relaciona via internet sem precisar de deslocamento espacial.

Nesse cenário atual, o que há, então, é uma descentralização do confinamento: a lógica da descentralização burocráticoadministrativa, no final das contas, remete todos a uma mesma raiz. O que haveria de revolucionário nisso? "O que está sendo implantado, às cegas, são novos tipos de sanções, de educação, de tratamento. Os hospitais abertos, atendimentos a domicílio" (DELEUZE, 1992, p. 216).

O mote agora é reduzir custos no cuidado dos corpos, diminuindo, inclusive, a circulação dos mesmos. A setorização do cuidado, a assistência 'de volta pra casa' apresentam-se, então, imbricados com a mesma lógica de corpos digitalizados, zapeando na rede: 'contentese com a sua inclusão digital, o seu óbito foi registrado'. Do mesmo modo, não é paradoxal, apesar de parecer, assistirmos, nos últimos 
20 anos, no Brasil e no mundo, um boom do encarceramento, como demonstram os dados apresentados por Wacquant (2001).

\section{Pesquisa, estratégia política e compromissos afetivos: a questão do método}

Que linhas, que dobraduras, que "artes do vivível" estão implicadas na construção e na análise de um problema de pesquisa? Um problema de pesquisa nunca está dado: nem de antemão nem a posteriori. Linhas emaranhadas e imprevisíveis, que nunca repetem sua própria forma, sem começo nem fim, parecem tecê-lo e, nessa tessitura - sem desconsiderar a importância de "manter cursos" e "conservar alguns focos" -, se encontram mil pontos, dos quais se pode bifurcar (CORAZZA, 2002).

Produzir uma caracterização do cotidiano do sistema prisional do Estado de Sergipe, mais especificamente da Casa de Detenção de Aracaju (CDA). Produzir uma caracterização do cotidiano do sistema de saúde mental do município de Aracaju, mais especificamente do Centro de Atenção Psicossocial (CAPS) para Álcool e outras Drogas $(A D)$, mais especificamente ainda, de como estas se articulam com certos modos de subjetivação de masculinidades dentro desse sistema. Produzir caracterizações que se apóiem em uma experiência de pesquisa marcada pela inserção sistemática e regular no campo, escapando aos estereótipos e às falsas imagens sobre as condições concretas de funcionamento dos sistemas carcerário e de saúde mental ${ }^{4}$.

Eis o enunciado, de difícil consecução, do objetivo das pesquisas aqui anunciadas. Tal objetivo requer uma cuidadosa discussão sobre método. No que se refere ao sistema prisional, pela opacidade e totalitarismo do tipo de organização em que nos inserimos. No que se refere ao sistema de saúde mental, no terreno da reforma psiquiátrica - em se tratando de uma pesquisa que ocorre num serviço substitutivo de saúde mental, CAPS AD -, pelo risco de se produzir uma discussão inócua, que não analise os limites e desafios de um movimento antimanicomial tomado de assalto pelo Estado, ou seja, que corre cotidianamente 0 perigo de se institucionalizar/burocratizar.

Parecendo óbvio, os dois últimos parágrafos supracitados, introdutórios da questão de método que aqui se seguirá, têm funcionado muito como as expressões bordão utilizadas nos sistemas de confinamento, que não só os prisionais: prontamente enunciada, a coisa se esgota em si e não faz derivar consequências efetivas. Diante de instituições totais e, não nos enganemos, das novas espacialidades e dispositivos de controle que funcionam no contemporâneo, a posição da pesquisa se deteriora ainda mais rapidamente até os limites de uma "sobreimplicação" (LOURAU, 
1987) de tal ordem que as análises são comprometidas de antemão, em geral pela 'natureza' dos dados com que se opera ou se pensa operar.

Dito isso, precisamos também enunciar como essas colocações se relacionam com certa atualização da produção do discurso científico no que se refere ao discurso de método: se estamos indo na contramão de perspectivas essencialistas e universalistas, se não se trata mais de produzir a "verdade", mas verdades circunstanciais, como falar em rigor? Qual o critério de cientificidade? O que pode sustentar a especificidade do discurso científico do ponto de vista do que interessa ao pensamento?

O rigor mantém-se na delimitação clara e distinta, mas dos procedimentos técnicos e das circunstâncias em que os objetos se constituem e as verdades se produzem. Uma densa descrição de procedimentos e a clara enunciação dos compromissos pelos quais se narra os acontecimentos é o que pode liberar o pensamento para outras trajetórias e outras aventuras, é onde se atualiza a especificidade do discurso acadêmico, é como se politiza o especialismo. Em última análise, o rigor é auferido pela efetivação do movimento estratégico. Qual é a nossa estratégia? Qual nosso interesse e posição político-afetiva? Como, a partir de uma experiência, produzimos verdades que sejam condizentes com os compromissos na rede de relações a partir da qual a experiência nos afeta?

A pesquisa científica é uma atividade social tão submetida quanto qualquer outra às condições sócio-históricas sob as quais se desenvolve, estando, assim, carregada de tonalidades políticoafetivas na trama de níveis de titulação, paixões, condições de financiamento, ciúmes e cumplicidades, "necessidade" de produtividade acadêmica, vaidades, interesses institucionais em relação ao eixo temático e, evidentemente, esquemas de exclusão e controle de perspectivas teórico-críticas. O problema de pesquisa é construído e abordado no bojo dessa trama, a partir de certa política de teorização e de vieses e compromissos afetivos, assumindo-se o ônus e o bônus de assim compor.

O método como uma operação do espírito, antes de sua redução a instrumentos e procedimentos, é aqui foucautiana estratégia rigorosa de enfrentamento de um risco, um problema, um paradoxo. Premissa política-afetivamente implicada a orientar a invenção de táticas/técnicas (instrumentos e procedimentos) que a efetivem. Aposta radical de um ponto de vista que nela arrisca tudo.

Em última análise, os instrumentos e as técnicas utilizados se constituem orientados pelo imperativo estratégico do método. Os procedimentos e instrumentos de uma pesquisa são da dimensão tática. O método, a estratégia, marca um interesse político desejante 
que a tática visa operacionalizar. O rigor na explicitação do movimento que se põe como modo de objetivação da dimensão político afetiva da estratégica em termos táticos de uma operacionalização metodológica em suas implicações conjunturais ocupa, aqui, o lugar de critério de cientificidade.

Assim, compondo com uma perspectiva teórico-metodológica de inspiração foucaultiana, entrelaçam-se gestos pesquisadores dimensão de existência que aparece no modo como estão selecionados e agrupados gestos de pessoas agindo segundo um esquema de funcionamento sujeito-pesquisador nos registros institucionais - e problemas de pesquisa: análise das formas de objetivação das assim chamadas 'políticas públicas' de segurança (mais especificamente o sistema prisional) e saúde mental (serviços substitutivos de saúde mental). Dito de outro modo, análise de como tais 'políticas' se articulam e compõem com o boom do confinamento. $\mathrm{Em}$ nossas inserções tropeçamos com práticas que indicam características de possíveis mudanças históricas singulares: as conversas com agentes prisionais, técnicos administrativos e gestores de diferentes escalões do sistema mostraram a concordância das análises informais destes com as análises feitas pelos 'internos'. Ninguém, com experiência neste sistema, defende, argumenta ou menciona com seriedade a tal função de 're-socialização', desde que informalmente.

Uma expressão que no âmbito do sistema prisional é quase gíria. Aparece em segmentos como 'Ah, mas segundo os princípios da resocialização [...]'; 'Ô? A gente não tá aqui para re-socializar? [...]', em situações referidas à distância entre o que um grupo de agentes prisionais chamou de o real e o oficial. Assim, o termo 'resocialização' aparece como marcador de conversações que sinalizam uma impossibilidade de seguir com uma linha de argumentação e raciocínio por se deparar com o descolamento do discurso da experiência comum, portal do 'sem sentido'.

Profissionais de saúde mental, usuários, familiares em CAPS, almejando produção de autonomia e cidadania, reabilitação psicossocial? Palavras ao vento, palavras institucionalizadas, jargões repetidos diariamente! Ao proclamá-las, parecemos continuar presos, como diria Chico Buarque, esperando, esperando o trem, esperando a morte, mesmo vivos, para esperar também. No entanto, pelo tempo que ocupam nos discursos gestores e pelos esforços em difundir informações sobre o sucesso das finalidades institucionais dos dois sistemas, fazem repensar hábitos de análise.

A pista veio da fala de um técnico de segundo escalão: “É uma sinuca de bico esse negócio de reabilitação pelo trabalho com tanto desemprego. Se dentro dos presídios a coisa funcionasse, ia ter gente cometendo crime para ter chance de ingressar no programa". 
Todos estamos cumprindo pena: a pena de subsumirmos nossos corpos a uma existência normalizada. Nossos corpos, virtualmente, são culpados. O corpo é um aberto de possibilidades e a culpa advém dos nossos corpos insistirem, na maioria das vezes de forma inconsciente, em extravasar as fronteiras desse possível préestruturado, dessa campânula de vidro em que nos colocaram.

Os corpos devem ser vigiados. Esses homens, usuários de álcool e outras drogas, usuários do CAPS AD, estão cumprindo pena: ao ousarem borrar e interrogar o ideal de limpidez, do 'tudo está sob o controle', dos corpos normais, corpos sãos, corpos fortes, corpos aptos, os corpos desses homens tornam-se corpos identificados, corpos abjetos, que nos oferecem o limite. Como? Limitando-os. Homens, corpos não cidadãos, agora adoecidos e não mais criminosos, devem cumprir pena não mais no presídio, não mais no hospital psiquiátrico, mas no CAPS.

Ir, frequentar o CAPS, essa é a pena a cumprir se desejam se tornar novamente cidadãos, consumidores, consumidores de políticas públicas. Lá, eles comem, bebem, dormem de dia, o que não podem muitas vezes fazer de noite; lá, para não perderem a vaga que ganharam na loteria, muitos fingem, até para si mesmos, querer voltar a ser "homem", ser trabalhador, homem honrado, bom filho, bom marido e bom pai; lá, eles cumprem penas.

'Nova cultura de cidadania', o famigerado projeto de ampliação da 'democracia participativa', alardeado pelos governos brasileiros dos últimos 10 a 12 anos, cria imagens de ações e dispositivos educacionais que seriam adotadas e desenvolvidas por 'organismos governamentais' e setores da 'sociedade organizada' visando uma mudança de cultura orientada pelo 'paradigma da Cidadania e dos Direitos Humanos'. Documentos relativos a ciclos de dispositivos sociopedagógicos direcionados ao funcionalismo estatal e/ ou terceirizado conhecido como conferências municipais, estaduais e nacionais de ... (saúde, educação, juventude, direitos humanos, segurança, etc.) são exemplos emblemáticos da modalidade discursiva que se tem em mente.

Malgrado a repetida retórica estatal, a complexidade - e decorrente grau elevado de dificuldade - de qualquer mudança cultural é dimensão incontornável própria ao ritmo histórico que caracteriza os processos de produção de valores e crenças em relação aos modos de funcionamento e às práticas cotidianas. Isto coloca o problema para além da facilidade com que é apresentado na propaganda oficial.

Assim, intervenções relativas aos modos de subjetivação, historicamente constituídos, próprios a uma sociedade, ou segmento desta, sempre foram desafios das ciências humanas. Está-se aqui em meio ao processo pelo qual os interlocutores formam ideias inéditas ou dão continuidade àquelas existentes - formação e transformação 
de ideias irredutíveis às características de um ou de outro interlocutor, só explicáveis pelo singular sócio-histórico da relação que os constitui.

Diante do acima posto, nossa proposta discute a hipótese de que ao invés de se pensar as mudanças de estilo gerencial dos últimos governos como uma abertura política, haveria, ao abrigo das imagens de 'abertura política' e 'aperfeiçoamento democrático', indícios de uma mudança nas funções societárias de três grandes sistemas de sustentação do 'estado de direito' no Brasil. Tal mudança criaria uma convergência da rede pública de escolas, serviços assistenciais de saúde e unidades prisionais nas implicações destes com a produção institucional de violência ${ }^{5}$ objetivada por uma 'atividade generalista' de encargo direto dos corpos, agrupada sob a rubrica de fluxograma do estado policial como função de 'serviço social'.

Pelo desempenho dessa nova função de encarregado direto pelos corpos se constituem 'saberes técnicos' relativos aos modos descentralizados de confinamento. Saberes comuns a professores de escolas públicas, enfermeiros e assistentes da rede pública de saúde, agentes de reeducação e resocialização.

Após alguns anos de pesquisa-interferência no Sistema Prisional e no Sistema de Saúde, aprendeu-se que a contradição enunciada na dupla função isolamento e reinserção compõe coerentemente a função institucional. $O$ fato da idéia de re-socialização pelo trabalho aparecer como falseta surgiu como analisador: se já não é mais para o trabalho, o que orienta as práticas de socialização em uma sociedade em que, como nunca cultuado e na mesma medida precarizado, o trabalho já não é valor absoluto?

Progressivamente suspeita-se: A) da morte do deus trabalho e imediatamente de sua forma de culto: a educação; B) da finalidade desta segunda: 'melhoria da qualidade de vida das populações'. Do mesmo modo, o que se faz então na rede de saúde - já que não é, pelo menos só e na maioria das vezes, produzir saúde? E na escola se já não é educação o que aí se ativa? E na prisão - pela eloquência da obviedade de que não é socialização o fazer no sistema prisional? Seguindo e construindo linhas labirínticas, a partir de nossas artes do vivível e de pesquisa, a construção do problema visou às condições sócio-históricas de produção e reprodução da função políticoinstitucional de encargo direto pelos corpos. Visou, ainda e, sobretudo, às possibilidades de re-existência pela ativação do desejo nos corpos, inclusive nos nossos. Trata-se de uma etno-interferência sobre os modos de dizer e fazer encontrados em diferentes estabelecimentos e organizações do sistema carcerário e de saúde mental. 


\section{Pesquisa-I nterferência}

Como fazer pesquisa transitando nos limites, por entre as disciplinas e saberes, na zona de indeterminação que entre eles se produz, atravessando velhos caminhos, na busca do que não foi percorrido? Como desenhar uma metodologia que implique o esforço de evitar simplificações reducionistas, cedendo lugar a uma nova forma de experimentação que indica o desafio de se superar o isolamento e comprometer-se com as pessoas?

O ponto de partida da nossa estratégia metódica consistiu em problematizar a invenção dos procedimentos de inserção, construção de dados e análise, seguindo as formulações mais recentes da sócio análise francesa (interferência) (LOURAU,1997) e a idéia de uma regra de adequação única do sentido das enunciações (indexabilidade) trazida pela Etnometodologia (GARFINKEL, 2001). Esse movimento resulta no que é aqui apresentada como 'etno pesquisa interferência' ou como 'etno-interferência'. Sugestões promissoras, ainda que discutíveis, pelo que estas buscam no sentido de inverter o problema e transformar a ligação com o campo de pesquisa em vantagem.

Há aqui o explícito interesse de manter o enfoque da relação de reciprocidade e simultaneidade entre 'produção de conhecimento', 'interferência' no processo estudado e implicações político-afetivas paradoxo de práticas especialistas que envolvem algum tipo de 'ação social', talvez não apenas destas. Isto não por uma propriedade que Ihes pertença, mas, sem dúvida, pelas capacidades e autoridades que os modos de recepção lhes atribui:

[...] temos outras urgências: não basta relativizar na pesquisa, como o antropólogo cultural; fazer dos documentos monumentos, como o historiador; conectar em rede, como o sociólogo, embora tenha sido em tais bibliotecas que aprendemos a suspeitar da maior parte do que é dito (e instado a fazer, pensar e ser) nas nossas. Somos necessariamente interventores diretos no campo social, dotados de "poderes que podem favorecer ou matar definitivamente a vida", mesmo quando agimos em nome de verdades científicas restritas ou locais. (RODRIGUES, 1998, p.45)

Por meio do que intitulamos de etno-interferência, é através da trama inserção-levantamento-caracterização-análises-discussão pública de alternativas que o movimento de pesquisa operacionalizado visa a constituição de uma dispositivo com capacidade analítica e potencial de interferência nas relações cotidianas. O objetivo - em um sentido fraco já que, humanamente, se rompe com a ilusão de que o futuro deva ser conforme o passado - é que as verdades construídas deixem 
de ser propriedade de especialistas e sirvam às pessoas diretamente vinculadas aos processos sociais em questão.

Mas, como se torna operatória a noção lourauniana de interferência? Falar em pesquisa intervenção, ou termo equivalente, leva ao risco de se cair, quase que automaticamente, em uma atitude militante, nos moldes de uma cruzada. Esta seria orientada por um tipo de 'teleologia da libertação', anunciando aos quatro ventos seus propósitos de romper com os grilhões que acorrentam os escravizados. A imagem estereotipada da 'pesquisa participante' se completa com a idéia de que ela estaria instrumentalizada por uma metodologia 'clarividencialista', capaz de iluminar tudo o que está no campo inacessível das trevas, dando, assim, 'consciência'.

Se não se trata de cruzada, não se trata também de abstrair acontecimentos cotidianos que nos envolvem. Ao contrário, a pesquisa nos aparece como alternativa político-afetiva de enfrentamento ao modelo das ações partidárias e/ou corporativas dos quais já se suspeita. Ilusões de um comum senso: escapar à usurpação dos interesses específicos, e ao vazio de certa gramática, se instrumentaliza taticamente pela tarefa de encontrar um campo de coerência conceitual que permita pensar acontecimentos no âmbito de organizações totais e dos modelos assistenciais, acionando um dispositivo de discussão coletiva das implicações situacionais com a lógica capitalística. Desse modo, imediatamente informado pelas circunstâncias da pesquisa, o pensamento se debate para escapar aos sentidos habituais de um cotidiano ubíquo (GUATTARI, 1992).

Como alternativa à noção de intervenção, que se articula a uma ação que se pretende completamente orientada por um objetivo préestabelecido, utilizamos a noção de interferência, a qual supõe uma ação que não intenciona antecipar 'o' sentido que sua aproximação com o campo de relações construirá, abrindo espaço para deixar-se surpreender com tal campo e, nele, com os sentidos produzidos a partir de tal interferência (ALTOÉ, 2004).

Questionando, então, o modelo e as implicações da pesquisaintervenção, no presente trabalho, o interesse maior se detém no tema das relações que constituem as ações de pesquisa, no caso específico, nos espaços de função pública em organizações totais e em modelos assistenciais.

Como pesquisa participante, em um sentido amplo do termo, aqui ficam acentuados dois aspectos: o primeiro, pensar o método como especificação sistemática de um proceder orientado por interesses de conhecimento singular de acontecimentos raros - Não se tratando de abordar processos regulares ou, dito de outro modo, sendo o caso de enfrentar os automatismos padronizados característicos da lógica capitalística, inclusive os automatismos de pesquisa, fica-se obrigado a um esforço de experimentação metodológica em busca de 
entendimento sobre processos sociais em estado de fusão. Concebese, portanto, a questão metodológica como estratégica no fazer pesquisante e não como um cargo de especialistas metodólogos:

[...] uma vez que o objeto de pesquisa da sociologia é a vida social na qual estamos todos envolvidos, a capacidade de fazer uso imaginativo da experiência pessoal e a própria qualidade da experiência pessoal de alguém serão contribuições importantes para a capacitação técnica desta pessoa. (BECKER, 1993, p.45)

O segundo aspecto implicado na noção de pesquisa participante, por conta mesmo do permanente estado de experimentação de como se concebe a pesquisa, surge a questão do tipo de pesquisador e do tipo de objeto de estudo que se especificam pela pesquisa.

Considerando o pesquisar como acontecimento sócio-histórico e, porque tal, executor, destinatário, instrumento de políticas, a tática de abordagem refere-se ao mapeamento da produção discursiva local e cotidiana, à análise de rotinas e automatismos padronizados que sustentam os funcionamentos instituídos. $O$ que se visa, estrategicamente, é um comentário sobre os jogos de linguagem (WITTGENSTEIN, 1994) que discuta as lógicas que os inspira. Neste plano, a pesquisa pôde tornar-se interferência à medida que colocava em análise, nos espaços das organizações de saúde e do sistema prisional, as imagens agostinianas ${ }^{6}$ postas como justificadoras dos modos de operar e os 'propósitos formalmente enunciados' da referida 'função pública'.

A partir das considerações realizadas, pode-se dizer que a pesquisainterferência insere-se num movimento mais amplo de re-orientação da pesquisa em ciências humanas, um movimento de rejeição de pretensões essencialistas e universalistas. Desse modo, a análise aspira e, quem sabe inspire, o surgimento de outros mundos por outras práticas.

A pesquisa passa, então, a se mover segundo algumas marcas específicas: a) foco na dimensão local dos eventos sociais, nas atividades mais ordinárias da vida cotidiana; b) compromisso com o circunstancial, tanto da pesquisa, quanto do pesquisador e modo de conceber o objeto de estudo/problema de pesquisa; c) aproximação e compromisso com o desejo nas pessoas; e d) operacionalização da interferência através de dois dispositivos inseparáveis: o dispositivo analítico e o articulacional, ou seja, o pesquisar uma atividade híbrida, porosa, como experimentação, negociação e composição entre pessoas, entre espaços paisagens, o pesquisante e sua trajetória atravessando relações - e não como interpretação de outra realidade circunscrita e a priori. 


\section{Pesquisa nesses espaços-tempos}

Sabe-se que, no contemporâneo das sociedades ocidentais, a lógica hegemônica é a capitalística. O modo de operar de tal lógica, ao transformar tudo e todos em valores intercambiáveis pelo equivalente universal, produz vazio de sentido, principalmente sob o âmbito do capitalismo financeiro em que tudo desincorpora. Isso leva ao limite o efeito de heteronomia das instituições em face às relações cotidianas. Diante disso, pensamos que uma possibilidade de (re)existência dáse através da ativação do desejo nas pessoas, tensionados contra os interesses institucionais.

O alvo da análise são conjuntos de lógicas abstratas de ordenamento das relações, articuladas em dispositivos de regulamentação da vida, as instituições. Tais feixes institucionais podem ser leis, normas e/ou pautas, formações discursivas através das quais se objetivam e se legitimam valores. Em outros termos, entendemos como instituições:

[...] não o estabelecimento ou local geográfico, mas relações e campos de força instituídos e produzidos - percebidos como naturais que se opõem constantemente a outros campos de força instituintes. Daí dizemos que as instituições diferentemente de como são vistas - não são estáticas, cristalizadas e, portanto, eternas. Estão em constante movimento, o que significa que podemos nelas interferir. (COIMBRA, 2001, p. 21-22)

Todavia, uma vez organizadas entre si, as instituições produzem uma sensação de estabilidade que tende a ser naturalizada e uma operação contínua de moralização. Nessa direção, aproxima-se o dilema institucional do dilema existencial:

[...] toda instituição impõe ao nosso corpo, mesmo em suas estruturas involuntárias, uma série de modelos, e dá à nossa inteligência um saber, uma possibilidade de previsão, assim como de projeto. Nós reencontramos a conclusão seguinte: o homem ${ }^{7}$ não tem instintos, tem instituições. O homem é um animal se despojando da espécie. Assim, o instinto traduziria as urgências do animal, e a instituição, as exigências do homem. [...] o tipo homem é um projeto de formação de instituições. (DELEUZE apud PAULON, 2006, p. 127)

As instituições e os modos de subjetivação - tomados aqui como "campos enrijecidos dos repertórios de subjetivação" - são vetor e suporte, duplamente, de um complexo poder-saber: produzem-se e naturalizam-se as instituições, produz-se e naturaliza-se certo tipo de subjetividade, certo tipo de produção desejante, um certo "percurso conformista do desejo ao processo moralizante das instituições" (PAULON, 2006, p. 124-125).

$\mathrm{Na}$ contramão de tal naturalização, intentamos afirmar o sentido de produção histórica dos processos de subjetivação e das instituições. 
Se instituições e subjetividades não são essências, naturezas, origens, cabe a lição de Castoriadis (2004, p. 159) ao falar do dispositivo grego da democracia:

\begin{abstract}
Esta ruptura pressupõe que esses mesmos indivíduos que foram fabricados por sua sociedade, que são fragmentos ambulantes, puderam se transformar essencialmente, puderam criar os meios de pôr em causa e em questão as instituições que haviam herdado, as instituições da sociedade que os formara.
\end{abstract}

Retomando a questão do método, qual seria nossa estratégia? Orientar a pesquisa pelo desejo das pessoas e não pelos interesses institucionais constitutivos da lógica capitalística. Procedendo ao desmonte dos automatismos padronizados pelo descrédito nas redundâncias retóricas prestidigitadoras da Verdade, principalmente aquelas dos enunciados jurídicos. Partindo da idéia de aprisionamento pelas 'imagens agostinianas' (WITTGENSTEIN, 1994), lembramos aqui das reflexões sobre a tautológia comunicativa apresentada por Lucien $\mathrm{Sfez}^{8}$, para entender os modos oportunísticos pelos quais a lógica do capitalismo financeiro se articula.

Mais uma vez, anuncia-se o escopo do nosso trabalho, das nossas pesquisas-interferências: tentar resistir, tentar furar o cerco da lógica capitalística, do tautismo comunicacional e dos automatismos tecnicistas, criando dispositivos de análise coletiva das implicações; produzir espaços-tempos em que os processos de institucionalização que nos constituem possam ser postas em questão.

São por nossas práticas, emergindo das relações dos homens e das mulheres, e não por fatos externos a nós, que se estabelecem a justiça e as injustiças (CASTORIADIS, 2004). Em linhas gerais, o método, no nosso caso, é a estratégia para explicitar essa questão, colocando em funcionamento esses espaços-tempos de análise coletiva das implicações e crítica às instituições, às lógicas que nos orientam na ordenação de nossas relações. É, então, no sentido de reativação do desejo nas pessoas, que se ressalta a importância de reativar os saberes locais, fazendo ruir o lugar imaculado do especialista e o seu poder de estabelecer A verdade do mundo, garantindo-se objetividade por meio do calculo técnico de base racional.

Desde o século XIX e ainda nos dias atuais, os regimes de verdade que vigoram nas sociedades ocidentais tendem a ser veiculados, dentre outros equipamentos sociais, pela ciência, mais especificamente um modo hegemônico e legitimado de fazer ciência, a saber, o positivista, com seus ideais de neutralidade, objetividade e universalidade. Este elege determinados discursos como verdadeiros e considera outros como falsos. Contrapondo-se ao ideário positivista, é que se intenta focar nos saberes locais: saberes dominados, 
descontínuos, não qualificados e não legitimados pelos discursos englobantes, hierarquizantes e totalizantes produzidos pela 'ciência'.

\begin{abstract}
Que tipo de saber vocês querem desqualificar no momento em que vocês dizem 'é uma ciência'? Que sujeito falante, que sujeito de experiência ou de saber vocês querem 'menorizar' quando dizem: 'eu, que formulo este discurso, enuncio um discurso cientifico e sou um cientista'? (FOUCAULT, 2001, p. 172)
\end{abstract}

Depois de aprender a falar na gíria do sistema, as duas pesquisas viram-se colocadas diante da questão da função efetiva do sistema: um confinamento de corpos que não se põe como segregação, uma vez que é o caso de Ihes permitir uma vida em separado. Segundo nossa hipótese, trata-se, antes, de manter tais corpos com a vida em suspenso, numa latência ancorada na promessa de vida no futuro. Confinamento do presente em uma temporalidade arrastada.

Nesse terreno de hegemonia do capitalismo tecnofinanceiro e sua tomada de poder sobre as subjetividades, re-existir descrendo, descreditando, extravasando as fronteiras desse possível préestruturado por nós habitado, eis a estratégia metódica para guerras com o vazio de sentido e com a naturalização/universalização. Indissociabilidade entre produção de conhecimento, pesquisa, política, afeto, em movimento transversal despido de concepções fundamentalistas; não restrita aos muros das especialidades. Pesquisa anti-normalizadora, desfocada da idéia de produção de verdades universais, um caminhar menor, marcado por singularidade e inventividade, eis o proposto.

Desmontar as estruturas institucionais sem que caiam por sobre as cabeças das pessoas. A estas, deixar em paz, e argumentar ferozmente contra os arcaísmos oportunistas, negando se, enquanto pesquisador, as encomendas institucionais de carceragem e encargo direto pelos corpos. Aliar-se entre pessoas para tentar o que não se pôde ainda, inclusive nos modos de fazer pesquisa.

\title{
Referências Bibliográficas
}

ALTOÉ, S. (Org.). René Lourau: analista institucional em tempo integral. São Paulo: Hucitec, 2004.

BAPTISTA, L, A. Narrações contemporâneas: vagabundos e turistas nas práticas da saúde mental. In: JACÓ-VILLELA, GREZZO; RODRIGUES (Org.). Clio-psyché hoje: fazeres e dizeres psi na história do Brasil. Rio de Janeiro: Relume Dumará; FAPERJ, 2001.

BAUMAN, Z. Globalização. Rio de Janeiro: J orge Zahar Editor, 1999. BECKER, H. S. Métodos de pesquisa em Ciências Sociais. São Paulo: Hucitec, 1993. 
CASTORIADIS, C. Figuras do pensável: as encruzilhadas do labirinto. Volume VI. Eliana Aguiar (trad.). Rio de Janeiro: Civilização Brasileira, 2004.

COIMBRA, C. Operação Rio: o mito das classes perigosas. Rio de Janeiro: Oficina do Autor; Niterói: Intertexto, 2001.

CORAZZA, S. M. Labirintos de pesquisa, diante dos ferrolhos. In: COSTA (Org.). Caminhos investigativos: novos olhares na pesquisa em educação. 2. ed. Rio de janeiro: DP\&A. 2002, p.105132.

DELEUZE, G. Conversações, 1972-1990. Rio de Janeiro: Ed. 34, 1992.

FOUCAULT, M. Microfísica do poder. 16. ed. Rio de Janeiro: Edições Graal, 2001.

A nova divisão. In:

clássica. São Paulo: Perspectiva, 2004.

História da loucura na idade GARFINKEL, H. Le programe de L'Etnometodologie. In: FORNEL, M. (Orgg.). L'ethnométhodologie - une Sociologie radicale. Paris: de la découverte, 2001, p.31-56.

GOFFMAN, Erving. Manicômios, prisões e conventos. 7.ed. São Paulo: Editora Perspectiva, 2001.

GUATTARI, F. Caosmose - um novo paradigma estético. Rio de Janeiro: Editora 34, 1992.

HARDT, M. A sociedade mundial de controle. In: ALLIEZ, E. (Org.). Giles Deleuze: uma vida filosófica. São Paulo: Editora 34, 2000. LOURAU, R. Implication: un nouveau paradigme? Socius, Paris, n. 4/5, p.191-213, 1987.

. La clé des champs. Paris: Ed. Anthropos. 1997.

PAULLON, S. A desinstitucionalização como transvaloração apontamentos para uma terapêutica do niilismo. Athenea Digital, v.10, p.121-136, 2006.

RODRIGUES, H. Quando Clio encontra Psyche: pistas para um (des) caminho formativo. Cadernos transdisciplinares do Instituto de Psicologia da UERJ, Rio de Janeiro, v.1, p. 3-69, 1998.

WACQUANT, L. As prisões da miséria. Rio de Janeiro: Zahar, 2001. WITTGENSTEIN, L. I nvestigações filosóficas. Petrópolis: Vozes, 1994.

\section{Endereço para correspondência}

Manoel Mendonça Filho

Rua Lagarto, 952, Centro, CEP 49010-390, Aracaju-SE , Brasil

Endereço eletrônico: mendoncafilho@ufs.br

Michele de Freitas Faria de Vasconcelos

Av. Paulo Gama, s/n, 12201, sala 511 (Geerge), Bairro Farroupilha, CEP 90046900, Porto Alegre-RS, Brasil.

Endereço eletrônico: michelevasconcelos@hotmail.com

Recebido em: 03/08/2009 
Aceito para publicação em: 23/12/2009

Acompanhamento do processo editorial: Deise Mancebo, Roberta Romagnoli e Marisa Lopes da Rocha

\section{Notas}

* Professor permanente do Núcleo de Pós-Graduação em Psicologia da UFS e do Núcleo de Pós Graduação em Educação da UFS

**Graduada em psicologia pela UFS, mestre em saúde coletiva pelo ISC/UFBA, bolsista CNPq; doutoranda em educação pela UFRGS, na linha de pesquisa Educação, Sexualidade e Relações de Gênero, bolsista CAPES.

${ }^{1}$ Capitalístico usado aqui no sentido dado por Guattari. Ver Caosmose. Rio de Janeiro: Ed. 34. 1992.

2 Saliente-se, porém, que, mesmo tidos como incapazes de produzir e, por isso, submetidos ao internamento, esses dois segmentos são atravessados pela lógica de produção capitalística: aos criminosos, destina-se 0 trabalho forçado nas workhouses; aos loucos, destina-se o trabalho terapêutico nos asilos psiquiátricos. Hoje, também costumam ser internados aqueles que transitam entre os dois rótulos, loucos e criminosos, a saber, os usuários de drogas.

${ }^{3} \mathrm{Em}$ aspas, Coimbra cita Wacquant

4 Os relatos das pesquisas mencionadas, bem como algumas linhas de argumentação, estão apresentados mais detalhadamente em 'A herança das galinhas: histórias e estórias do sistema prisional em Sergipe' Mendonça Filho, 2009 e 'Por uma genealogia das políticas de inclusão de saúde mental contemporâneas: da produção de políticas identitárias e de modos variados de confinamento' Michele Vasconcelos e Mendonça Filho, ambos In: Política e

Afetividade: narrativas e trajetórias de pesquisa. MENDONÇA FILHO, M. e NOBRE, M. T. Salvador/Aracaju: EDUFBA/EDUFS. 2009.

${ }^{5}$ A noção de violência institucional está apresentada e discutida em "violência institucional e função educativa no estado do capitalismo financeiro", MENDONÇA FILHO, M. Educação e Cidadania: questões contemporâneas. In: Neves, P. Educação, Cidadania: Questões contemporâneas. São Paulo: Cortez. 2009.

${ }^{6}$ No sentido Wittgensteiniano discutido em MORENO, A. Wittgenstein através das imagens. Campinas: Ed.UNICAMP. 1993.

7 É através da naturalização desses mesmos modelos que tendemos a resumir a Humanidade, com " $\mathrm{H}$ " maiúsculo, a uma forma-homem articulada a imagens de homem, masculino, branco, viril, chefe de família, trabalhador, consumidor, empreendedor, sadio, útil ao capital.

${ }^{8}$ Ver Sfez, L. Crítica da Comunicação. São Paulo: Loyola, 1994. 